\title{
Commentary: Efficacy of Clorpactin in refractory bladder pain syndrome/interstitial cystitis: a randomized controlled trial
}

\author{
Mittal Patel ${ }^{1}$ (D) \\ Received: 5 January 2021 / Accepted: 9 February 2021 / Published online: 11 March 2021 \\ (C) The International Urogynecological Association 2021
}

The management of bladder pain syndrome/interstitial cystitis (BPS/IC) is often arduous, requiring a multi-disciplinary approach combining treatment of lifestyle and dietary modifications with pharmacological oral and/or intra-vesical treatments. Although there are numerous intra-vesical treatments available, none has proven greater efficacy over another.

This study is a multi-centre, single-blinded randomized controlled trial [1] investigating the use of Clorpactin instillation in patients with refractory BPS/IC. This is particularly important owing to the current lack of good-quality evidence for the use of Clorpactin which, although reported to be effective in patients with BPS/IC since 1955, lacks controlled trials and is associated with caustic effects. This led to it being an unpopular treatment in BPS/IC.

This study randomised 50 subjects, 25 to Clorpactin instillation ( $0.4 \%$ solution, $2 \mathrm{~g}$ in $500 \mathrm{ml}$ of normal saline) and 25 to hydrodistension ( $500 \mathrm{ml}$ or less of normal saline alone under $80 \mathrm{~cm} \mathrm{H}_{2} 0$ pressure for $4 \mathrm{~min}$ ) in patients undergoing cystoscopy under general anaesthesia. The primary outcome was based on Global response Assessment (GRA) at 3 months. Secondary outcomes included the O'Leary Sant Symptom Index (OLSI) and the O'Leary Sant Problem Index (OPLI) questionnaire scores, visual analogue scale (VAS) score for pain and bladder diary parameters.

Follow-up was complete in 22 women receiving hydrodistension and 16 receiving Clorpactin. At 3 months, GRA improvement of "much better" or "very much better" was noted in $56 \%$ of subjects in the Clorpactin group versus only $4.5 \%$ of subjects in the hydrodistension group $(p=$
0.001). Both the OLSI and the OLPI were significantly improved/lower at 3 months in the Clorpactin group but not in the hydrodistension group. Of note, there was a $>50 \%$ reduction in VAS pain scores in $56 \%$ of subjects in the Clorpactin group versus no reduction in the hydrodistention group.

It is important to note that Clorpactin was associated with higher rates of same-day admissions and re-admissions ( 8 and 6 out of 25 respectively) compared with hydrodistension, which was associated with 3 out of 25 patients requiring same-day admissions and no subjects requiring re-admission. This study suggests that Clorpactin therapy in BPS/IC subjects provides improved short-term symptom relief over hydrodistension. This study provides a foundation for future research to be done comparing Clorpactin with other instillation agents.

\section{Reference}

1. Cvach K, Rosamilia A, Dwyer P, Lim Y, DeSouza A, Ow L, Thomas E, Murray C, Leitch A, Schierlitz L. Efficacy of Clorpactin in refractory bladder pain syndrome/interstitial cystitis: a randomized controlled trial. Int Urogynecol J. https://link. springer.com/article/10.1007/s00192-020-04652-3

Publisher's note Springer Nature remains neutral with regard to jurisdictional claims in published maps and institutional affiliations.
Mittal Patel

m.patel6@nhs.net

1 St Mary's Hospital, Imperial College Healthcare NHS Trust, London, UK 